\title{
School Makerspace Manifesto
}

\author{
Giovanni Nulli $\mathbb{D}$
}

\begin{abstract}
This contribution describes a sustainable model for makerspaces in primary and lower secondary schools. Based on Indire research on innovative school spaces, it discusses the theoretical background that schools should adopt and create before starting a makerspace lab. It also looks at which aspects of the maker culture can successfully be combined with active pedagogy. In this way, educational institutions and makers can come together to build makerspaces within schools that will be useful to both.
\end{abstract}

Keywords Makerspace $\cdot$ Maker culture $\cdot$ Active pedagogy $\cdot$ Sustainable model Primary and lower secondary schools

\section{Why a Makerspace Manifesto for Primary and Lower Secondary Schools}

Indire has worked in several fields of study that can be considered part of the maker culture: 3D printers, robotics and coding. As part of our research into innovative spaces within schools, we also carry out observations in schools that have built makerspaces.

We consider the maker movement and the literature that it has engendered to be an important stimulus for schools. We believe the maker culture's approach to knowledge and its emphasis on practical learning are good ingredients for a new curriculum. It is important to emphasize that we consider maker culture to be related to active pedagogy. It can create an upward spiral of innovation in the curriculum and teaching methods.

Thus, active schools and the maker movement can find each other, if both parties adhere to certain conditions.

\section{G. Nulli (凶)}

Istituto Nazionale di Documentazione, Innovazione e Ricerca Educativa (Indire), Florence, Italy e-mail: g.nulli@indire.it 


\section{The Potential Relationship Between Schools and Makers}

We propose the manifesto from the case study we led in 2018 at Secondo Istituto Comprensivo Montessori Bilotta in Francavilla Fontana (Brindisi) and at the Istituto Comprensivo Largo Castel Seprio (now called Istituto Comprensivo Lucio Fontana) in Rome, published in Guasti and Nulli [1, p. 94-110]. Both schools have an active makerspace and both collaborate with external maker associations.

Schools and makers are two very broad, diverse and elaborate entities. Yet, as long as they can find common ground, they can create a lab where they can work together but also separately, according to their individual needs. For schools, this will be their institutional mission, which is closely related to the national curriculum; for makers, it is having a sustainable business model.

To understand why maker culture can successfully work in schools, we will look at what a maker is.

\subsection{What is a Maker?}

The Maker Movement Manifesto [2] and the Makerspace Playbook, second edition [3], describe the mindset of a maker:

1. Someone who uses their intelligence, knowledge and skills to create things;

2. Someone who learns what they need to for their projects;

3. Someone who shares their knowledge, because they believe sharing to be a fundamental facet of learning;

4. Someone who uses (and builds) tools, however simple or technological;

5. Someone who enjoys the process;

6. Someone who enjoys working with others and considers it mutually beneficial, because each may have skills that others need;

7. Someone who encourages others, because they believe everyone can get results.

We think this kind of mindset can be very useful in schools where teachers apply active pedagogy.

\section{Three Principles on Which Makers and Active Schools Can Agree Before Building a Makerspace}

We think schools and makers should agree on three principles before they begin collaborating. These are:

1. Recognizing the complexity of the world: creating ties and developing divergent thinking;

2. Showcasing knowledge: spreading it, and encouraging self-knowledge building; 
3. Interacting with the environment and objects: intelligent artifacts and meaningful environment.

\subsection{Recognizing the world's Complexity}

Complexity is a key word in contemporary science. Morin [4, p. 27] defined it as an "empty word" used whenever something "is not simple, is not clear, is neither black nor white, when appearances might be deceptive, there may be doubts, we don't really know". ${ }^{1}$ He referred to this as the "sphynx-complexity" (ibid., p. 70), indicating that it is something that should be questioned like an oracle.

In contemporary science, the emerging complex world is asking for a change in the paradigms of knowledge. For the purposes of this short work, we assume that specialist knowledge, divided into in-depth topics, does not fully grasp "the complex," and that the structure of knowledge itself ${ }^{2}$ is no longer adequate. Therefore, an interdisciplinary approach and practical work are needed. Individual cases and points of view are more important than generalization when dealing with "the complex."

In our opinion, the maker's mindset comes from this "complex world," and the following steps represent this point quite well:

1. The objective of knowledge is to create; knowledge and creation are closely linked.

2. Team work is necessary: different points of view are needed, because there is no such thing as absolute knowledge.

3. Object creation is contingent on time and resources.

4. Having fun, because the creator's point of view is important.

If maker culture reflects the meaning of a complex world, what about schools? Are there any links to aspects of knowledge that are so theoretical?

The National Curriculum Guidelines [6, p. 11] talk about "quadri d'insieme" ("overall pictures;" from the chapter "Per un nuovo umanesismo"-For a new humanism — 3 the most "Morinian" part of the Italian Curriculum). This calls for a broader vision of learning in which schools have to create local curricular paths that bring different subjects together. Therefore, schools that already create these paths and promote the integration of students' attitudes, experiences and knowledge into their school curriculum are best placed to understand the maker's point of view, and offer students a means for questioning "sphynx-complexity."

For schools, it means that the maker way of doing things is not so distant, and there are affinities for starting a long-term shared project, such as a makerspace.

\footnotetext{
${ }^{1}$ My own translation from the Italian edition.

${ }^{2}$ In Morin [5, p. 17] (My own translation from the Italian edition): "We are not aware that the disjoining and fractioning of knowledge limits [...] our opportunities to understand ourselves and our world, which cause a "knowledge pathology".

3 "For a new humanism", my own translation.
} 


\subsection{Showcasing Knowledge}

Both the maker culture and schools are focused on knowledge, but they need to have more in common in order to build a connection. There are many different ways of being a maker, just as there are different ways for schools to carry out their mission, and manage knowledge. Here are some aspects that are similar for makers and schools and which give a sense of self-built knowledge that circulates.

For makers:

1. Knowledge is closely linked to personal experience and specific people.

2. Learning is fundamental and building a new object is a learning process.

3. Sharing objects and the process of building them is sharing knowledge: information about your own project can be gleaned from someone else's.

4. Open hardware and software means that the more knowledge circulates the more knowledge is available.

For schools:

1. Creating learning paths that are as personalized as possible.

2. Using competence learning, where knowledge is linked to context.

3. Promoting autonomous learning.

4. Teachers let students follow their own paths, while supporting and stimulating them, and asking them questions.

The form of knowledge emerging from the previous steps is something that is selfcreated by someone who explores, collaborates and builds, rather than something that already exists somewhere for the purpose of being transmitted. If we consider the learning path to be a voyage, knowledge is not the destination, but the voyage itself, where teachers are more experienced voyagers.

\subsection{Interacting with the Environment and Objects}

Makers use tools and create objects. For them, technology is both virtual and real. It is virtual because they share documentation, codes and projects through creative commons licenses. It is real because they use the most innovative tools for production, such as $3 \mathrm{D}$ printers and laser cutters.

What about schools? With the exception of laboratory work, traditional lessons involve very few tools. Active pedagogy can use the environment, tools and technological tools.

The following shows how makers and schools can meet each other in the physical world.

Makers need physical space:

1. To share beyond the virtual space.

2. To share machinery and tools. 
3. To meet people, share ideas and hold courses.

Active schools (which, of course, exist in a physical space) need to give a pedagogic significance to their space and enable students to use several tools:

1. To develop active methods with objects (and to enrich interactions with technology and intelligent tools).

2. To leave students free to move as a way of fostering responsibility and autonomy.

3. To develop a pedagogic use of the environment as an area in which teachers can practice active pedagogy and share a pedagogic vision with each other.

If all of the above conditions are met, schools can start collaborating with a maker (association, group, etc.) on the design and implementation of a makerspace.

\section{Starting Point and Sustainable Model}

If a school wants to create a makerspace, it can be helpful to collaborate with an external group of makers. If the two can agree on the previous point, the project can go ahead. At this stage, the school principal, advised by the maker, should consider the following steps:

1. Check whether the school already has a space that is perhaps underused. Be creative.

2. It is important, almost imperative, that the chosen place has its own entrance.

3. Find/create a group of teachers the maker can train.

4. Involve people from outside the school, including public stakeholders and parents; let economic stakeholders know about the new makerspace; inform other schools; contact all important stakeholders in the local community.

The maker and the school can sign a pact and build a makerspace within school to their mutual benefit, as we can see in the following table.

The mutual benefits begin with the initial condition (first line, Table 1) and the first steps: the school finds a place, and the maker advises on machines and furniture, and creates a purchasing plan based on funds collected. Once the first step is completed, they can proceed to the second step: the school is a socially recognized stakeholder

Table 1 Mutual benefit, in order of time

\begin{tabular}{l|l}
\hline School gives maker & Maker gives school \\
\hline $\begin{array}{l}\text { 1. A place to share and create his/her activity } \\
\text { 2. Advertising in the form of social recognition }\end{array}$ & $\begin{array}{l}\text { 1. Technical and design advice } \\
\text { and development }\end{array}$ \\
\hline $\begin{array}{l}\text { 3. Expertise on course-building for } \\
\text { teachers/students; curricular knowledge }\end{array}$ & $\begin{array}{l}\text { 3. Support to teachers for designing new } \\
\text { lessons; support to teachers during lessons } \\
\text { in the makerspace }\end{array}$ \\
\hline
\end{tabular}


in relationship with other subjects. The maker can use the makerspace outside school time (especially if it has an independent entrance), for meetings or for courses for external personnel. This enables the maker to build her own business model. The maker can then hold technical training courses for teachers, while providing lab maintenance and development services, including planning new purchases.

The third step is a process of consolidation between the maker and the school. At this stage, the maker has a deeper understanding of how the school works and is able to design second-level courses, which address curricular needs. She also works for other schools as an expert, selling courses for teachers. On the other hand, the maker can be integrated into the school's activities, providing support for a new kind of lesson that bridges the makerspace activity and the school curriculum. She acts as an atelierista, as described by pedagogue Malaguzzi [7, p. 88], providing structured support to the teacher in the space and in the lesson design.

\section{Why a Makerspace? Because It is a Disruptive Way to Make Change}

Neil Gershenfeld (director of the Center for Bits and Atoms and author of the 2005 book "Fab: the coming revolution on your desktop-from personal computer to personal fabrication") identified Seymour Papert as one of the founding fathers of the maker movement [8, p. 163]: "The distinction between toys and tools for invention, [culminates] in the integration of play and work in the technology for personal fabrication. The original inspiration and instigator for bringing these worlds together was Seymour Papert, a mathematician turned computer pioneer." (own translation). We would like to conclude this work with Papert's words [9, p. 27 and 26] about active pedagogy and innovation in schools: "John Dewey's idea that children would learn better if learning were truly a part of living experience; or Freire's idea that they would learn better if they were truly in charge of their own learning processes; or Jean Piaget's idea that intelligence emerges from an evolutionary process [...]. Sadly, in practice they just wouldn't fly. When educators tried to craft an actual school based on these general principles, it was as if Leonardo had tried to make an airplane out of oak and power it with a mule [...]. In my view almost all experiments purporting to implement progressive education have been disappointing because they simply did not go far enough in making the student the subject of the process rather than the object [...]. Early designers of experiments in progressive education lacked the tools that would allow them to create new methods in a reliable and systematic fashion". 4 What Papert advocated was that active methods should be adopted along with all the repercussions and changes they bring. He also upheld the need to drive the system towards using as many tools as technology (in a wide sense) can offer, even if it means having to retrain teachers. Teachers should be prepared to come out of their comfort zones in order to invest in a different future.

4 "For a new humanism", my own translation. 
In our opinion and experience, building a makerspace is the sort of economic investment that causes the kind of disruption that leads to more stable long-term change.

\section{References}

1. Guasti G., Nulli G., Tosi, L.: Creare un makerspace: i casi dell'IC Largo Castelseprio e del Secondo IC Montessori Bilotta. In: Tosi L. (ed.) Fare didattica in spazi flessibili, Giunti Scuola, Florence (2019)

2. Hatch, M.: The Maker Movement Manifesto. S. 1. McGrawHill education (2014)

3. Makespace Team: Makerspace Playbook, 2nd edn. S. 1. Maker Media (2013). Retrieved 2020/09/21 https://makered.org/wp-content/uploads/2014/09/Makerspace-Playbook-Feb2013.pdf

4. Morin E.: La sfida della complessità, Editoriale Le Lettere, Florence (2017)

5. Morin, E.: La conoscenza della conoscenza. Saggi/Feltrinelli, Milan (1989)

6. MIUR: Indicazioni Nazionali per il Curricolo, Rome, Le Monnier (2012)

7. Edwards C., Gandini L., Forman G.: I cento linguaggi dei bambini, Parma, Spaggiari Edizioni (2017)

8. Gershenfeld, N.: Fab: the coming revolution on your desktop-from personal computer to personal fabrication. Basic Books, New York (2005)

9. Papert, S.: I bambini e il computer. Rizzoli, Bologna (1994)

10. Papert, S.: The Children's Machine: Rethinking School in the Age of the Computer. Basic Books, New York (1992)

Open Access This chapter is licensed under the terms of the Creative Commons Attribution 4.0 International License (http://creativecommons.org/licenses/by/4.0/), which permits use, sharing, adaptation, distribution and reproduction in any medium or format, as long as you give appropriate credit to the original author(s) and the source, provide a link to the Creative Commons license and indicate if changes were made.

The images or other third party material in this chapter are included in the chapter's Creative Commons license, unless indicated otherwise in a credit line to the material. If material is not included in the chapter's Creative Commons license and your intended use is not permitted by statutory regulation or exceeds the permitted use, you will need to obtain permission directly from the copyright holder. 